\title{
Is antenatal care preparing mothers to care for their newborns? A community-based cross-sectional study among lactating women in Masindi, Uganda
}

Richard Mangwi Ayiasi ${ }^{1 *}$, Simon Kasasa ${ }^{1}$, Bart Criel${ }^{2}$, Christopher Garimoi Orach ${ }^{1}$ and Patrick Kolsteren ${ }^{2}$

\begin{abstract}
Background: Neonatal mortality has remained resistant to change in the wake of declining child mortality. Suboptimal newborn care practices are predisposing factors to neonatal mortality. Adherence to four ANC consultations is associated with improved newborn care practices. There is limited documentation of this evidence in sub-Saharan Africa where suboptimal newborn care practices has been widely reported.

Methods: Structured interviews were held with 928 women having children under-five months old at their homes in Masindi, Uganda, from October-December 2011. Four/more ANC consultations (sufficient ANC) was considered the exposure variable. Three composite variables (complete cord care, complete thermal care and complete newborn vaccination status) were derived by combining related practices from a list of recommended newborn care practices. Logistic regression models were used to assess for associations.

Results: One in five women 220(23.7\%) were assessed to practice complete cord care. Less than ten percent 57(6.1\%) were considered to practice complete thermal care and 611(65.8\%) were assessed to have complete newborn vaccination status. Application of substance on the cord 744 (71.6\%) and early bathing 816 (87.9\%) were main drivers of sub-optimal newborn care practices. Multivariable logistic models did not demonstrate significant association between four/more ANC consultations and complete cord care, complete thermal care or complete newborn vaccination status. Secondary or higher education was associated with complete cord care [adjusted Odds Ratio (aOR): $2.72 ; 95 \% \mathrm{Cl}: 1.63-4.54$ ] and complete newborn vaccination [aOR: 1.37; 95\% Cl: 1.04-1.82]. Women who reported health facility delivery were more likely to report complete thermal care [aOR: 3.63; 95\% Cl: 2.21-5.95] and newborn vaccination [aOR: 1.84; 95\% Cl: 1.23-2.75], but not complete cord care. Having the first baby was associated with complete thermal care [aOR: 2.00; 95\% Cl: 1.24-3.23].

Conclusion: Results confirm suboptimal newborn care practices in Masindi. Despite being established policy, adherence to four or more ANC consultations was not associated with complete cord care, complete thermal care or complete newborn vaccination. This finding has important implications for the implementation of focused ANC to improve newborn care practices. Future ANC interventions should focus on addressing application of substance on the cord and early bathing of the baby during the immediate neonatal period.
\end{abstract}

\footnotetext{
* Correspondence: mangwirichard@gmail.com

${ }^{1}$ Makerere University School of Public Health, College of Health Sciences,

Kampala Uganda, P. O. Box 7072, Kampala, Uganda

Full list of author information is available at the end of the article
} 


\section{Background}

Neonatal mortality has remained resistant to change $[1,2]$. Most causes of neonatal death are preventable and relate to cord care to decrease sepsis, temperature control and initiation of early breastfeeding which has the additional benefit of controlling hypothermia [3]. Good assisted deliveries can decrease delivery complications, stillbirth and early neonatal deaths [4]. Initiation of BCG and polio vaccination within the first four weeks after birth [5-7] can enhance neonatal survival.

One of the instruments to obtain reduction in neonatal mortality is Antenatal Care (ANC), where we now agree that the risk identification approach [8-10] is not the important reason. Rather, the preparation of pregnant women to become knowledgeable mothers [11] hence limiting the number of visits to four (at four, six, eight and nine months) [12] if no complications are anticipated $[13,14]$. ANC delivery should have as an important objective to inform and prepare women to care correctly for their newborn. Two mutually reinforcing interventions should be packaged and offered to pregnant women during ANC consultations. First, the more technical intervention which includes history taking, clinical examinations, laboratory investigations, treatment and assessment for referral [5]. Second, health education and counselling which entails dialogue that creates an interface between medical conditions and socially relevant issues regarding ANC such as promotion of healthy lifestyles among pregnant women, birth plans including preparation for unexpected events and preparation for parenting especially care for the newborn [15]. Throughout the ANC period information about physical and psychological preparation for the newborn is offered to pregnant women [6]. This process of communication is expected to progressively make the women better mothers.

Evidence in Asia indicates that information on newborn care practices offered to pregnant women and their families during ANC clinics leads to improved care practices (complete cord care, complete thermal care and initiation of breastfeeding within one hour) $[16,17]$. In order to achieve similar results, focused ANC whereby pregnant women are encouraged to make at least four ANC consultations, has been widely promoted in Uganda.

In Uganda, the coverage of focused ANC services has been scaled up to all tiers of the healthcare system with the aim of increasing awareness about birth preparedness, promoting supervised delivery and improving newborn care practices. Today, about $48 \%$ of pregnant women make four ANC consultations or more while 57\% seek delivery assistance from a health facility $[18,19]$. However, recent studies conducted in Uganda have reported suboptimal newborn care practices [20-23] and stagnated neonatal mortality rates [24]. Moreover, little is known about the relationship between newborn care practices and attending four ANC consultations.

This study specifically assessed newborn care practices with regards to thermal care, cord care and newborn vaccination status among lactating women in Masindi district in Uganda and determined its relationship with adherence to four or more ANC consultations.

\section{Methods}

\section{Study design and setting}

In a cross sectional design, lactating women with babies aged less than five months in Masindi and Kiryandongo districts were visited in their homes from October to December 2011. Similar studies conducted in Uganda have used age limits of less than five months [20]. At the time of conceptualizing this study, Masindi and Kiryandongo districts had one administrative unit, Masindi district and split to form two districts three months prior to data collection. We will therefore describe them assuming the original administrative unit by June 2011, hence Masindi district. Cluster survey was preferred to allow for generalizability to the entire district. Parishes were considered the sampling unit for this study. A parish in Uganda is a geographical area occupied by about 10,000 - 20,000 inhabitants.

Masindi district is located about 214 kilometres northwest of the capital city Kampala. The district population is 603,000 and about half $(49.1 \%)$ are female. The population is predominantly rural with about $5.4 \%$ being urban. Administratively, Masindi district is divided into three counties (Buruli, Kibanda and Bujenje), eight sub counties and 41 parishes.

In Uganda, health care delivery in the public sector is decentralized to the district level. There are four tiers of care at the district level: general hospital, health centres at the county-level (health centre of level IV), sub county level (health centre of level III) and parish level (health centre of level II). The village health teams (an informal structure) based at the community provide a linkage between the community and the health centre of level II $[25,26]$. All health centres are mandated to offer ANC [25,27]. As a minimum requirement, each parish should be served by a health centre of level II.

In Masindi district there are two general Hospitals and one sub district hospital (Masindi, Kiryandongo and Bwijanga respectively), 16 health centres of level III and 26 health centres of level II. Health centre of level II offers ambulatory care services and treatment for mild illnesses. Health centre level III provides ambulatory care, in-patient and laboratory services. Hospitals are referral centres for the district health system. About $90 \%$ (37/41) of the parishes in Masindi district have a functional health centre as recommended by the Ministry of Health in Uganda and 80\% of the population live within a 
five-kilometre walking distance to the nearest health centre [26]. In this region, routine data from the Health Management Information System indicates that $89.4 \%$ of pregnant women make at least one ANC consultation [28].

\section{Sample size and data collection procedures}

The sample size was estimated using a standard formula for cluster surveys [29]. The prevalence of good cord care practices in the region was estimated to be $42 \%$ (based on similar studies conducted in eastern Uganda) [20], design effect of 2 and sample error at 5\%. This yielded 18.7 clusters with a minimum sample size of 748 . Adjusted for $10 \%$ none response, 823 participants from 21 clusters needed to be recruited.

List of parishes (clusters) were obtained from the planning department in Masindi district and 21 of them were randomly selected using computer-generated random numbers. At the parish level, local council leaders guided research assistants to households with lactating women having children less than five months old because we did not have a documented list of women of reproductive age nor did we have a list of women who had delivered. Structured interviews were held with consenting women in their homes. Where a household had two or more lactating women, only one was randomly enrolled. Data collected included socio-demographic characteristics, previous obstetric history and history of last pregnancy, immediate newborn care practices and immediate postnatal care-seeking practices in case of neonatal illness (see Additional file 1). Three primary outcome variables were considered of interest- cord care, thermal care and newborn vaccination status. None of the eligible mothers contacted declined participation.

Before data collection for the main survey, the questionnaire was pre-tested in the neighbouring Hoima district. Pre-test data were collected from 30 women in three parishes.

\section{Data analysis}

Each questionnaire was checked for completeness before entry into Epidata software version 3.02. Double data entry was carried out and the two data sets were validated in the same software to eliminate entry errors. Analysis was carried out in STATA version 10.0. Sociodemographic characteristics, reproductive health indicators and selected newborn care practices were displayed using descriptive statistics. The number of ANC consultations during the last pregnancy was considered the exposure variable of interest and was coded as sufficient ANC attendance $=1$ defined as having made four ANC consultations or more and insufficient ANC attendance $=0$ defined as 1 to 3 antenatal consultations. Composite variables were generated from primary responses using the egen command in stata to constitute our primary outcome variables of interest. Outcome variables included complete cord care (defined as - used clean instrument to tie the cord, used clean instrument to cut the cord and applied salt water/nothing on the cord), complete thermal care (defined as - dried the newborn before the placenta or immediately after the placenta was delivered, wrapped the baby immediately the placenta was delivered and delayed bathing of the baby 24 hours or later after delivery) and complete newborn vaccination (a newborn baby who has received both tuberculosis and Polio zero vaccines routinely administered at birth). For purposes of our analysis we considered as complete cord care if any three of the five possible responses were correct, complete thermal care if any three of the four responses were correct and complete newborn vaccination if any one of the four possible outcomes were correct.

Independent variables considered during analysis were age (grouped as adolescents 15-19 years or adults 20-32 years), parity (having the first baby or having two or more babies), and marital status (living with spouse or living alone), source of income (regular or irregular source of income), level of education (attained no education/ primary level only or secondary/and higher education level) and place of delivery (in health facility or delivered outside of health facility). The category 'no education' were grouped together with 'primary education' because we did not consider any difference between the two groups [30].

The chi-square test was used at the bivariate level of analysis. Independent variables with corresponding $p$-values of 0.4 or less were fitted into a logistic regression model. Number of antenatal care consultations was purposively maintained into the multi-variable model for each outcome variable of interest even when their corresponding $p$-value was greater than the significant levels because this was our primary exposure of interest. The svyset stata command was used to take care of the cluster effect of our data collection technique whereby people from the same geographical location tend to provide similar responses.

\section{Ethical consideration}

A written consent was secured from all mothers before participation and confidentiality was guaranteed. This study was approved by the Higher Degrees Research and Ethics Committee of the School of Public Health, Makerere University and Uganda National Council for Science and Technology (Ref: HS 1145).

\section{Results}

Nine hundred and twenty-eight lactating women were interviewed. Their mean age was 25.5 years $[S D=6.3$ : [95\% CI: 25.1-25.9]. Nearly a fifth $175(18.9 \%)$ were women between 14 and 19 years old and one fifth 187(20.2\%) were 
Table 1 Socio-demographic characteristics of mothers with children under five months $(n=928)$

\begin{tabular}{ll}
\hline Variable & $\mathbf{n}(\%)$ \\
\hline Age group & $175(18.9)$ \\
14-19 years & $753(81.1)$ \\
20-45 years & $25.5[6.3]$ \\
Mean age (Standard Deviation) & \\
Parity & $187(20.2)$ \\
One child & $170(18.3)$ \\
Two children & $139(15.0)$ \\
Three children & $117(12.6)$ \\
Four children & $112(12.1)$ \\
Five children & $203(21.9)$ \\
More than five children & \\
Education level of mother & $186(20.0)$ \\
Non & $590(63.6)$ \\
Primary & $143(15.4)$ \\
Secondary & $9(1.0)$ \\
Tertiary &
\end{tabular}

\section{Marital status}

Married/living with partner

Single

Separated

Widowed

Source of income

Subsistence farming

Commercial farming

Self employed

Salaried job

Women reporting death of at least a child

None

One

Two

Three

More than three

Time of death of babies $(n=235)$

Stillbirths

1-7 days after birth

7-28 days

More than 28 days after

Where the baby's death occurred from $(n=235)$

Health facility

Home

Number of ANC visits made

None

One

$197(22.2)$

$608(65.5)$

109 (11.8)

$14(1.5)$

$693(74.7)$

$141(15.2)$

$23(2.4)$

$8(0.9)$

$36(15.3)$

$13(5.6)$

$8(3.4)$

$178(75.7)$

$135(57.4)$

$100(42.6)$
Table 1 Socio-demographic characteristics of mothers with children under five months $(\mathbf{n}=\mathbf{9 2 8})$ (Continued)

\begin{tabular}{ll} 
Two & $146(15.7)$ \\
Three & $297(32.0)$ \\
Four & $252(27.2)$ \\
Five or more & $140(15.1)$ \\
Sufficient ANC visits & \\
None & $27(2.9)$ \\
$1-3$ visits & $509(54.9)$ \\
$>=4$ visits & $392(42.2)$ \\
Place of delivery & \\
Home & $532(57.3)$ \\
Health facility & $396(42.7)$ \\
\hline
\end{tabular}

having their first baby. Majority $831(89.6 \%)$ lived together with their spouse, 608(65.5\%) practiced subsistence farming. A quarter (235/928) of the women reported having lost at least one child in the years preceding the current baby. One in every four deaths $(57 / 235)$ occurred in the first 28 days most of them early and were still births, while 57 percent of the deaths occurred in a health facility.

Two in five 42.2\% (392/928) made four ANC consultations or more and a similar proportion 42.7\% (396/928), reported giving birth in a health facility. Other characteristics of the mothers interviewed are presented in Table 1.

$63(6.8)$

\section{Newborn care practices}

We examined newborn care practices among lactating women (Table 2) with a specific focus on cord care, thermal care and newborn vaccination status. Three in four women (702/928) used clean material for tying the cord, 92.2\% (856/928) used clean instruments for cutting the cord, while $28.4 \%(264 / 928)$ applied salty water/ nothing on the cord. About three out of five (542/928) dried their baby before/soon after the placenta was delivered, half (451/928) wrapped the baby before the placenta was delivered and 12.1\% (112/928) reported delayed bathing of their baby by 24 hours or more after birth. By the time of the interview $84.3 \%$ and $64.8 \%$ of the babies had received BCG and Polio 0 vaccines respectively. The desired newborn care practices were assessed to be $23.7 \%$ (220/928) for complete cord care, 6.1\% (57/928) for complete thermal care and $65.8 \%$ (611/928) for complete newborn vaccination status.

\section{Cord care}

Results in the bivariate analysis for complete cord 27 (2.9) $\quad$ care (Table 3) indicate that education level $[\mathrm{OR}=2.89$ : 66 (7.1) $\quad p<0.001]$ and place of delivery [OR $=1.88: p=0.032]$ were positively associated with complete cord care. Implying 
Table 2 Newborn care practices $(\mathbf{n}=928)$

\begin{tabular}{ll}
\hline Variable & $\mathbf{n}(\%)$ \\
\hline Cord Care & \\
Material used for tying umbilical cord & \\
$\quad$ Clean thread & $702(75.7)$ \\
$\quad$ Unclean household cloth & $226(24.4)$ \\
Instrument used for cutting umbilical cord & \\
$\quad$ New razor blade & $534(57.5)$ \\
Sterile instrument & $322(34.7)$ \\
Old razorblade/household instruments & $72(7.8)$ \\
Application of substance on umbilical cord & \\
$\quad$ Baby powder & $576(62.1)$ \\
Animal waste & $5(0.5)$ \\
Soot Powder & $26(2.8)$ \\
Herbs & $57(6.1)$ \\
Salt water/Spirit or alcohol & $65(7.0)$ \\
Nothing & $199(21.4)$ \\
Cord Care &
\end{tabular}

Incomplete cord care

Complete cord care

708 (76.3)

$220(23.7)$

\section{Thermal care}

Warmth for the new-born/drying of the baby

Before the placenta is delivered

$336(36.2)$

After the placenta is delivered

After the delivery is complete

Baby not dried just wrapped

Warmth for the new-born/wrapping of the baby

Before the placenta is delivered

After the placenta is delivered

Long after the delivery has been concluded

Warmth for the new-born/Timing of first bathing

Immediately after delivery of the baby

Within 6 hrs. of delivery

7-23 hrs. after delivery

Second day or later

\section{Thermal care}

Incomplete thermal care

Complete thermal care

\section{Immunisation status}

Immunisation

Received BCG

Did not receive $B C G$

Received Polio 0

Did not receive Polio 0

Incomplete newborn vaccination

Complete Newborn vaccination
$349(37.6)$

$213(23.0)$

$254(27.4)$

$112(12.1)$

871 (93.9)

57 (6.1)

$782(84.3)$

$146(15.7)$

$601(64.8)$

$327(35.2)$

317 (34.2)

$611(65.8)$

that having attended higher level of education and delivered in the health facility was significantly associated with providing complete cord care. Source of income $[\mathrm{OR}=0.48: p=0.005]$ was negatively associated with complete cord care.

Independent variables included into a multivariable level analysis for complete cord care were sufficient ANC visits, age of the mother, education level, and place of delivery and woman's main source of income. In the adjusted analysis (Table 3) women who practiced commercial farming [(46\%): $p=0.021]$ were less likely to report complete cord care. While women that had attained at least secondary education [(172\%): $p=0.001]$ were more likely to report complete cord care, adjusted for age and place of delivery. Sufficient ANC visit was not significantly associated with reporting complete cord care $(\mathrm{aOR}=0.96: p=0.837)$.

\section{Thermal care}

Preliminary analysis showed that women who were having their first baby $(\mathrm{uOR}=2.28: p=0.001)$ and women who delivered in the health facility $(\mathrm{uOR}=3.72: p<0.001)$ were more likely to report complete thermal care. For further analysis the variables age, education, parity, delivery place and occupation were included in to the multivariable model for complete thermal care (Table 4). Sufficient ANC visit was maintained as the exposure variable of interest. Mothers who were having their first child [(100\%): $p=0.007$, had a health facility delivery [(263\%): $p<0.001]$ were more likely to report complete thermal care adjusting for age, education level and main source of income; implying that having the first child and delivering in the health facility were positively associated with reporting complete thermal care. Sufficient ANC consultation was not associated with reporting complete thermal care $(\mathrm{aOR}=1.07: p=0.858)$.

\section{Vaccination status}

In relation to newborn vaccination status (Table 5), sufficient ANC visits $(\mathrm{uOR}=1.50: p=0.024)$, having attained secondary education or higher $(\mathrm{uOR}=1.75: p=0.001)$ and reporting delivery at health facility $(\mathrm{uOR}=2.13: p<0.001)$ were significantly associated with reporting complete newborn vaccination status. At the multivariable level, having attained secondary education or higher [37\%: $p=0.029$ ] and women who delivered in the health facility [84\%: $p<0.001$ ] were significantly associated with reporting complete newborn vaccination status adjusted for age and parity. The level of statistical significance was not sustained for making sufficient ANC visits when adjusted for age and parity $(\mathrm{aOR}=1.34: p=0.133)$.

\section{Discussion}

Our data confirm sub-optimal newborn care practices for cord, thermal and vaccination status of the newborn. 
Table 3 Complete cord care and demographic characteristics

\begin{tabular}{|c|c|c|c|c|c|c|}
\hline Variable & Incomplete cord care n (\%) & Complete cord care n (\%) & UOR [95\% Cl] & $p$-value & aOR $[95 \% \mathrm{Cl}]$ & $p$-value \\
\hline \multicolumn{7}{|l|}{ Sufficient ANC** } \\
\hline $1-3$ visits & $389(76.4)$ & $120(23.6)$ & 1.0 & & & \\
\hline$>=4$ visits & $298(76.0)$ & $94(24.0)$ & $1.02[0.70-1.95]$ & 0.902 & $0.96[0.65-1.41]$ & 0.837 \\
\hline \multicolumn{7}{|l|}{$\mathrm{Age}^{* *}$} \\
\hline $14-19$ yrs. & $139(79.4)$ & $36(20.6)$ & 1.0 & & & \\
\hline $20-42$ yrs. & $569(75.6)$ & $184(24.4)$ & $1.25[0.80-1.95]$ & 0.310 & $1.22[0.82-1.83]$ & 0.313 \\
\hline \multicolumn{7}{|l|}{ Marital status } \\
\hline Not living with spouse & $76(78.4)$ & $21(21.7)$ & 1.0 & & & \\
\hline Living with spouse & $632(76.1)$ & $199(24.0)$ & $1.14[0.74-1.76]$ & 0.536 & & \\
\hline \multicolumn{7}{|l|}{ Education ${ }^{* *}$} \\
\hline Non or primary & $620(79.9)$ & $156(20.1)$ & 1.0 & & & \\
\hline Secondary plus & $88(57.9)$ & $64(42.1)$ & $2.89[1.72-4.45]$ & 0.000 & $2.72[1.63-4.54]$ & $0.001^{*}$ \\
\hline \multicolumn{7}{|l|}{ Parity } \\
\hline Two or more & $566(76.4)$ & $175(23.6)$ & 1.0 & & & \\
\hline First child & $142(75.9)$ & $45(24.1)$ & $1.02[0.70-1.49]$ & 0.906 & & \\
\hline \multicolumn{7}{|l|}{ Place of delivery** } \\
\hline Home & $432(81.2)$ & $100(18.8)$ & 1.0 & & & \\
\hline Health facility & $276(69.7)$ & $120(30.3)$ & 1.88 [1.06-3.32] & 0.032 & $1.54[0.84-2.81]$ & 0.150 \\
\hline \multicolumn{7}{|l|}{ Source of income ${ }^{* *}$} \\
\hline Subsistence farming & $128(65.0)$ & $69(35.0)$ & 1.0 & & & \\
\hline Commercial farming/regular income & $580(79.3)$ & $151(20.7)$ & $0.48[0.30-0.78]$ & 0.005 & $0.54[0.32-0.90]$ & $0.021^{*}$ \\
\hline
\end{tabular}

**For initial inclusion in multivariable model; ${ }^{*}$-is less than 0.05 ; UOR = unadjusted odds ratio; aOR=adjusted odds ration; (95\% $\mathrm{Cl}$ ) Confidence Interval at $95 \%$.

Thermal care ranked least practiced followed by cord care. Newborn vaccination was relatively better practiced. Women who reported last delivery being at a health facility were more likely to report complete thermal care and complete newborn vaccination status. But health facility delivery was not a good predictor of complete cord care. Studies conducted in Bangladesh suggest increasing the number of skilled birth attendants as an effective strategy to increase safe delivery practices [31]. Indeed there is a general consensus that access to skilled attendants at delivery has multiple benefits for the mother-baby pair [32]. Studies conducted elsewhere show that women who delivered in health facilities were more likely to report the practice of recommended newborn care [31,33]. Community interventions may help to reinforce recommended cord care practices initiated from the health facility to mitigate the problem of incomplete cord care identified in our study.

\section{Cord care}

From our results, the main determinant of complete cord care was application of potentially infectious substance on the cord. Majority of such substances are applied in the homes after discharge from a health facility and away from the supervision of a qualified health worker.
Our results are comparable to Waiswa and others in eastern Uganda, where only 38\% of the women [20] and in Bangladesh where $42.8 \%$ of the women were considered to have practised good cord care [31]. Elsewhere, application of substance on the cord was reported to face the greatest resistance to change [34,35]. Future cord care interventions should explore alternative substances that could be safely applied to the cord [36]. Women who had attained secondary education or more were more likely to report complete cord care. Similar studies conducted in Bangladesh found that secondary education was significantly associated with recommended newborn care practices including good cord care [33]. Women that were engaged in commercial farming or had a regular income, though counter-intuitive, were less likely to report complete cord care. It is possible that women who are engaged in commercial farming and earning regular incomes are more often absent from their homes and thus less available for child care.

\section{Thermal care}

Less than one in ten of the mothers were judged to practice recommended thermal care. Our results are comparable to another study conducted in Bangladesh where $5.1 \%$ were judged to have complete thermal care [31]. In 
Table 4 Complete thermal care and demographic characteristics

\begin{tabular}{|c|c|c|c|c|c|c|}
\hline Variable & $\begin{array}{l}\text { Incomplete thermal } \\
\text { care } \mathrm{n}(\%)\end{array}$ & $\begin{array}{l}\text { Complete thermal } \\
\text { care } \mathrm{n}(\%)\end{array}$ & UOR $[95 \% \mathrm{Cl}]$ & $p$-value & aOR $[95 \% \mathrm{Cl}]$ & $p$-value \\
\hline \multicolumn{7}{|l|}{ Sufficient ANC** } \\
\hline $1-3$ visits & $481(94.5)$ & $28(5.5)$ & 1.0 & & & \\
\hline$>=4$ visits & $364(92.9)$ & $28(7.1)$ & $1.32[0.61-2.85]$ & 0.458 & 1.07 [0.50-2.30] & 0.858 \\
\hline \multicolumn{7}{|l|}{$\mathrm{Age}^{* *}$} \\
\hline 14-19 yrs. & $161(92.0)$ & $14(8.0)$ & 1.0 & & & \\
\hline $20-42$ yrs. & $710(94.3)$ & $43(5.7)$ & $0.70[0.43-1.12]$ & 0.130 & $1.13[0.59-2.17]$ & 0.696 \\
\hline \multicolumn{7}{|l|}{ Marital status } \\
\hline Not living with spouse & $90(92.8)$ & $7(7.2)$ & 1.0 & & & \\
\hline Living with spouse & 781 (94.0) & $50(6.0)$ & 0.82 [0.29-2.30] & 0.697 & & \\
\hline \multicolumn{7}{|l|}{ Education** } \\
\hline None/primary & $733(94.5)$ & $43(5.5)$ & 1.0 & & & \\
\hline Secondary plus & $138(90.8)$ & $14(9.2)$ & 1.73 [0.89-3.32] & 0.098 & $1.08[0.45-2.57]$ & 0.857 \\
\hline \multicolumn{7}{|l|}{ Parity** } \\
\hline Two or more & $704(95.0)$ & $37(5.0)$ & 1.0 & & & \\
\hline Having First child & $167(89.3)$ & $20(10.7)$ & 2.28 [1.50-3.47] & 0.001 & 2.00 [1.24-3.23] & $0.007^{*}$ \\
\hline \multicolumn{7}{|l|}{ Place of delivery** } \\
\hline Home & $516(97.0)$ & $16(3.0)$ & 1.0 & & & \\
\hline Health facility & $355(89.7)$ & $41(10.4)$ & 3.72 [2.34-5.93] & 0.000 & 3.63 [2.21-5.95] & $0.000^{*}$ \\
\hline \multicolumn{7}{|l|}{ Occupation** } \\
\hline Subsistence farming & $182(92.4)$ & $15(7.6)$ & 1.0 & & & \\
\hline Commercial farming/regular income & $689(94.3)$ & $43(5.8)$ & $0.74[0.41-1.32]$ & 0.291 & $0.95[0.53-1.71]$ & 0.869 \\
\hline
\end{tabular}

**For initial inclusion in multivariable model; * $p$-less than 0.05 UOR= unadjusted odds ratio; aOR=adjusted odds ration; (95\% $\mathrm{Cl}$ ) Confidence Interval at $95 \%$.

our study, early bathing of the baby within the first 24 hours following birth was the main driver for the low thermal care practices. In eastern Uganda, a similar study found that nearly all mothers had bathed their babies within the first 24 hours after delivery [20]. A set of interlinked procedures referred to as the "warm chain" suggest the provision of warmth to the newborn from the time of birth and throughout the neonatal period [7]. Delayed bathing is one component of the warm chain. A controlled study conducted in Uganda demonstrated that early bathing significantly lowered neonatal body temperatures even when bathed with warm water and later applied skin-to-skin warming for the baby [23]. Moreover, in one hospital set up in Uganda $80 \%$ of the babies were recorded to have hypothermia within the first two hours following delivery [22]. Unfortunately, the practice of bathing the baby immediately after delivery [37] and delayed drying and wrapping [38] have also been encouraged by health workers based at the hospital. Another study that explored thermal care offered to newborns in Ghana suggests that interventions should be based on understanding of current behaviours and beliefs and must focus on messages and approaches in order to overcome barriers to behaviour change [39]. Indeed one study conducted in southern Uganda showed that most of the newborn care practices like thermal care are readily acceptable [21] by recently delivered women although other aspects of care like early bathing and application of substance to the cord are still resisted as they contravene societal cultural norms [40].

\section{Newborn vaccination status}

Newborn vaccination compared with cord and thermal care was better practiced. This may be in part due to the higher attention health workers accord to vaccination during prenatal care and immediate postnatal period [41]. Our results demonstrate that complete newborn vaccination status was significantly related to having health facility delivery and mother having secondary education or higher. This is in agreement with studies conducted elsewhere in Uganda [42,43] and in Kenya [44]. These studies further showed that children with several siblings were more likely to have untimely vaccinations. Our study showed positive relationship between women having their first baby and reporting complete newborn vaccination although our results were not statistically significant. This difference could have been as a result of studying different age groups. Their study enrolled 
Table 5 Complete newborn vaccination and demographic characteristics

\begin{tabular}{|c|c|c|c|c|c|c|}
\hline Variable & $\begin{array}{l}\text { Incomplete newborn } \\
\text { vaccination } \mathbf{n}(\%)\end{array}$ & $\begin{array}{l}\text { Complete newborn } \\
\text { vaccination } \mathrm{n}(\%)\end{array}$ & UOR $[95 \% \mathrm{Cl}]$ & $p$-value & aOR $[95 \% \mathrm{Cl}]$ & $p$-value \\
\hline \multicolumn{7}{|l|}{ Sufficient ANC** } \\
\hline $1-3$ visits & $191(37.5)$ & $318(62.5)$ & 1.0 & & & \\
\hline$>=4$ visits & $112(28.6)$ & $280(71.4)$ & 1.50 [1.06-2.13] & 0.024 & 1.34 [0.91-1.99] & 0.133 \\
\hline \multicolumn{7}{|l|}{$\mathrm{Age}^{* *}$} \\
\hline 14-19 yrs. & 65 (37.1) & $110(62.9)$ & 1.0 & & & \\
\hline $20-42$ yrs. & $252(33.5)$ & $501(66.5)$ & $1.17[0.91-1.52]$ & 0.202 & $1.25[0.94-1.66]$ & 0.115 \\
\hline \multicolumn{7}{|l|}{ Marital status } \\
\hline Not living with spouse & $31(32.0)$ & $66(68.0)$ & 1.0 & & & \\
\hline Living with spouse & $286(34.4)$ & $545(65.6)$ & 0.90 [0.50-1.60] & 0.695 & & \\
\hline \multicolumn{7}{|l|}{ Education $* *$} \\
\hline None/ Primary & $280(36.1)$ & $496(63.9)$ & 1.0 & & & \\
\hline Secondary plus & $37(24.3)$ & $115(75.7)$ & $1.75[1.29-2.38]$ & 0.001 & 1.37 [1.04-1.82] & $0.029^{*}$ \\
\hline \multicolumn{7}{|l|}{ Parity** } \\
\hline Two or more & $256(35.0)$ & $482(65.1)$ & 1.0 & & & \\
\hline Having First child & $58(31.0)$ & $129(69.0)$ & $1.20[0.76-1.87]$ & 0.417 & $1.37[0.72-2.61]$ & 0.323 \\
\hline \multicolumn{7}{|l|}{ Place of delivery** } \\
\hline Home & $219(41.2)$ & $313(58.8)$ & 1.0 & & & \\
\hline Health facility & $98(24.8)$ & $298(75.2)$ & 2.13 [1.47-3.08] & 0.000 & $1.84[1.23-2.75]$ & $0.005^{*}$ \\
\hline \multicolumn{7}{|l|}{ Occupation } \\
\hline Subsistence farming & $71(36.0)$ & $126(64.0)$ & 1.0 & & & \\
\hline Commercial farming/ Regular income & $246(33.7)$ & $485(66.4)$ & $1.11[0.72-1.72]$ & 0.622 & & \\
\hline
\end{tabular}

**For initial inclusion in logistic model; * $p$-is less than 0.05 ; UOR = unadjusted odds ratio; aOR = adjusted odds ration; (95\% $\mathrm{Cl}) \mathrm{Confidence} \mathrm{Interval} \mathrm{at} 95 \%$.

children 10-23 months old while our study considered children less than five months old.

\section{Policy implications}

Consistently, adherence to four or more ANC visits did not show statistically significant relations with newborn care practices implying that ANC is not delivering on the desired newborn care practices. We expected that women who adhered to recommended four ANC consultations would report better newborn care practices compared to those non-adherent mothers. This finding raises important questions about the organization and offer of ANC education already highlighted in a separate study conducted in the same region [41]. It further has implications for implementing the policy guidelines suggested by WHO for a comprehensive mother-newborn care package $[45,46]$, the policy on focused ANC and subsequently the practices of newborn care.

WHO recommends at least four ANC consultations during pregnancy with a specific focus for every visit [5] hence focused ANC [47]. The focus of these visits are a comprehensive package that includes five main elements: 1) recognition and management of pregnancy related complications; 2) recognition and treatment of concurrent conditions; 3) screening for conditions and diseases; 4) preventive measures like administration of tetanus toxoid and intermittent presumptive treatment of malaria; 5) advice and support to the woman and her family for healthy home behaviours and birth preparation plans, self care, recognition of danger signs, early care seeking, emotional and physical preparation for birth and care for the baby.

Clearly, the first four packages are clinically oriented requiring the input from skilled personnel like a midwife, but the fifth element which pertains to advice and support may not necessarily require such high level skills. We hypothesize that health workers in Masindi are more inclined to offer clinically oriented services at the expense of less technical services like health education $[39,48]$. Even when some women made adequate contact with the health care system during pregnancy they remained inadequately prepared for newborn care also demonstrated in a separate paper [41]. Health workers could inadvertently ignore components of ANC that relate to advice and support to the mother and their family including immediate newborn care. For example, a study in western Kenya showed that provision of palpation and vaccination during antenatal care were over $90 \%$ while those 
who received health education were only $14.4 \%$ [49]. In eastern Uganda, mothers interviewed could not recall any information given to them on pregnancy or newborn care [39]. In a multi-country study [50] in Africa, less than 50\% of the women reported they did not receive any educational information regarding danger signs in pregnancy leading to the delays in seeking for care in case of complications. Contrary to our findings, women who completed three or more ANC visits in Bangladesh were more likely to report having practiced recommended newborn care [31]. Also in Bangladesh a study conducted among the ultra-poor populations suggests that specific subclass of people required a tailored educational intervention in order to attain a behaviour change in the uptake of preand post-natal services [51]. It is possible that health workers in Masindi do not consider these unique aspects of the women while offering information regarding newborn care.

\section{Strengths and limitations}

Composite variables were derived from the different aspects of newborn care practices therefore introducing a measure of consistency in the recommended care practices. Individual care practices considered separately would somehow be misleading; for example over $90 \%$ of mothers reported using clean instruments for cutting the cord and yet only one third did not apply harmful substances on the umbilical cord. We hasten to add that while a composite measure gives more accurate measures of newborn care practices, most of these practices are beyond control of the mother alone. For example, the person who offers delivery care will tie the cord and cut the cord without necessarily any input from the mother. In the same way drying, wrapping and bathing of the baby remains under the control of the person assisting her in the delivery or the relatives who will attend to her soon after delivery. This may in part explain why delivering in a health facility was a predictor of thermal care and newborn vaccination. Nevertheless, a mother is likely to have a stronger influence over the newborn care interventions at the time of delivery if she has been adequately prepared with the correct information during ANC consultations [52].

In Uganda the Expanded Program on Immunization recommends the offer of vaccination for BCG and Polio 0 at birth although WHO provides a timeframe between zero to 8-weeks for BCG and zero-4 weeks in case of Polio 0. Our study could have under-estimated the vaccination status for newborns given that some of the babies were still within the age range of zero and 8 weeks. However, we think that mothers who had not had their babies vaccinated by the time of this study were also less likely to have a timely vaccination $[44,53]$.

Creation of a binary outcome for ANC consultations means grouping together one and three ANC consultation, yet making three ANC consultations are not necessarily equivalent to making one visit. We attempted to analyze separately for one, two, three, four or more consultations but could not establish any gradient (results not shown). The data collected were self-reported some women could have offered incorrect information due to recall bias. Direct observations could have mitigated this limitation in our study.

\section{Conclusion and suggestions}

Our results reaffirm the suboptimal newborn care practices. Application of potentially harmful substance on the cord and early bathing of the newborn are some of the drivers of inappropriate newborn care practices. Contrary to recommendations by the World Health Organization, this study could not demonstrate that adherence to four or more ANC consultations is an independent predictor of complete cord, complete thermal care or complete newborn vaccination. This has important implications for the implementation of the policy of focused ANC.

These findings ought to be interpreted with caution and within the context of the Ugandan local health system. We suggest further enquiry into the content and scope of prenatal services offered to pregnant women during ANC consultations in Masindi district. Application of substance and early bathing of the baby should receive priority attention during the immediate neonatal period (0-72 hours).

\section{Additional file}

Additional file 1: Data collection tool for lactating women.

\section{Abbreviations}

ANC: Antenatal care; BCG: Bacillus Calmette-Guérin; WHO: World Health Organisation.

\section{Competing interests}

The authors declare that there is no competing interests.

\section{Authors' contributions}

RMA, BC, CGO and PK conceptualized and designed the study. RMA entered the data; RMA, SK and PK analyzed the data. RMA, SK and PK wrote the manuscript. All authors read and approved the approved the final manuscript.

\section{Acknowledgement}

We thank the women for participating in this study and the research assistants that participated in data collection. This study was financed through the framework agreement between the Institute of Tropical Medicine, Antwerp, the School of Public Health, Makerere University and the Ministry of Health of Uganda. The field work was supported by the District Health Officers Dr John Turyagaruka and Dr Imaam Mutyaba and Mr John Kirungi of the Community Health department of Masindi District Hospital. We acknowledge the

coordinating support offered by Valeria Campos Da' Silveira and Dr. Batwala Vincent for reviewing the draft manuscripts.

\section{Author details}

${ }^{1}$ Makerere University School of Public Health, College of Health Sciences, Kampala Uganda, P. O. Box 7072, Kampala, Uganda. ${ }^{2}$ Institute of Tropical Medicine, Antwerp Nationalestraat 155, B-2000 Antwerp, Belgium. 
Received: 11 January 2013 Accepted: 14 March 2014

Published: 25 March 2014

\section{References}

1. Lawn JE, Cousens S, Zupan J: 4 million neonatal deaths: when? Where? Why? Lancet 2005, 365(9462):891-900.

2. Knippenberg R, Lawn JE, Darmstadt GL, Begkoyian G, Fogstad H, Walelign N, Paul VK: Systematic scaling up of neonatal care in countries. Lancet 2005, 365(9464):1087-1098

3. Gary LD, Bhutta ZA, Cousens S, Taghreed A, Neff Walker, Luc de Bernis, Team ftLNSS: Evidence-based, cost-effective interventions: how many newborn babies can we save? Lancet 2005, 365:977-988

4. Martines J, Paul VK, Bhutta ZA, Koblinsky M, Soucat A, Walker N, Bahl R, Fogstad H, Costello A: Neonatal survival: a call for action. Lancet 2005, 365(9465):1189-1197.

5. WHO: Standards for Maternal and neonatal care development. World Health Organisation. Geneva: Department of Making pregnancy safer; 2002.

6. WHO: Partnership for maternal newborn \& child health. A global review of the key interventions related to reproductive maternal, newborn and child health (RMNCH). Geneva: World Health Organisation; 2011.

7. WHO: Thermal Protection for the newborn: a practical guide. In World Health Organisation. Geneva: Maternal and newborn health/safe motherhood unit; 1997. WHO/RHT/MSM/97.2.

8. WHO: Risk Approach for Maternal and Child Health care. A managerial strategy to improve the coverage and quality of maternal and child health/family planning services based on the measurement of individual and community risk. World Health Organisation, Geneva; 1978. Offset Publication No. 39.

9. WHO: Risk approach for maternal and child health care. World Health Forum 1981, 2(3):413-422.

10. Bergsjo $P$ : What is the evidence for the role of antenatal care strategies in the reduction of maternal mortality and morbidity?". In Studies in Health Services Organisation \& Policy. Edited by Van Lerberghe W, Kegels G, De Brouwere V. Safe Motherhood Strategies; 2011. vol. 17 35-54; 2011.

11. Villar J, Ba'ageel H, Piaggio G, Lumbiganon P, Miguel Belizan J, Farnot U, Al-Mazrou Y, Carroli G, Pinol A, Donner A, Langer A, Nigenda G, Mugford M, Fox-Rushby J, Hutton G, Bergsjo P, Bakketeig L, Berendes H, Garcia JWHO, Antenatal Care Trial Research Group: WHO antenatal care randomised trial for the evaluation of a new model of routine antenatal care. Lancet 2001, 357(9268):1551-1564.

12. WHO: Pregnancy, childbirth postpartum and newborn care. In World Health Organisation. Geneva: A guide for essential practice(Integrated management of pregnancy and childbirth); 2006

13. WHO: WHO Antenatal care randomised trial: Manual for the implementation of the new model. In World Health Organisation. Geneva: Department of Reproductive Health and research family and community health; 2002.

14. WHO: Standards for maternal and neonatal care. In Department of Making Pregnancy Safer. World Health Organisation; 2006.

15. WHO: Making every mother and child count. In The World Health Report 2005. Geneva: World Health Organisation; 2005.

16. Damstadt GL, Zulfiqar AB, Cousens S, Taghreed A, Neff W, Luc de Bernis, Team ftLNSS: Evidence-based, cost-effective interventions: how many newborn babies can we save? Lancet 2005, 365:977--988.

17. Vishwajeet K, Aarti K, Gary LD: Behavior Change for Newborn Survival in Resource-Poor Community Settings: Bridging the Gap Between Evidence and Impact. Seminars in perinatology 2010. doi:10.1053/j. semperi.2010.09.006

18. UDHS, ICF: Uganda Demographic and Health Survey. In Uganda Bureau of Statistics, Kampala Uganda 2011, Uganda Bureau of Statistics (UBOS) and ICF International Inc. Kampala, Uganda: UBOS and Calverton, Maryland: ICF International Inc; 2012

19. UDHS: Uganda Demographic and Health Survey. In Uganda Bureau of Statistics. Government of Uganda, Kampala Uganda: (UBOS); 2006.

20. Waiswa P, Peterson S, Tomson G, Pariyo GW: Poor newborn care practices - a population based survey in eastern Uganda. BMC Pregnancy Childbirth 2010, 10:9.

21. Byaruhanga RN, Nsungwa-Sabiiti J, Kiguli J, Balyeku A, Nsabagasani X, Peterson S: Hurdles and opportunities for newborn care in rural Uganda. Midwifery 2010. doi:10.1016/j.midw.2010.1002.1005.

22. Byaruhanga R, Bergstrom A, Okong P: Neonatal hypothermia in Uganda: prevalence and risk factors. J Trop Pediatr 2005, 51(4):212-215.
23. Bergstrom A, Byaruhanga R, Okong P: The impact of newborn bathing on the prevalence of neonatal hypothermia in Uganda: a randomized, controlled trial. Acta Paediatr 2005, 94(10):1462-1467.

24. $\mathrm{MOH}$ : Road Map for accelerating the reduction of maternal and neonatal mortality and morbidity in Uganda 2006-2015. Government of Uganda, Ministry of Health Kampala, Uganda; 2010a.

25. MOH: Heath Sector Strategic Plan III 2010/11-2014/15. In Government of Uganda, Ministry of Health Kampala, Uganda; 2010b.

26. $\mathrm{MOH}$ : The second National Health Policy: promoting people's health to enhance socio-economic development. The Republic Uganda. Kampala, Uganda: Ministry of Health; 2010c.

27. $\mathrm{MOH}$ : In Situation Analysis of Newborn health in Uganda: Current status and opportunities to improve care and survival. Edited by Save the Children, UNICEF, WHO. Kampala: Government of Uganda; 2008.

28. DHO: Masindi district annual plan and budget. Uganda: District Health Office Masindi; 2010.

29. Bennet S, Woods T, Liyanage MW: A simplified general method for cluster-sample surveys of health in developing countries. World Health Stat Q 1991, 44:98-106.

30. Atuyambe L, Mirembe F, Tumwesigye NM, Annika J, Kirumira EK, Faxelid E: Adolescent and adult first time mothers' health seeking practices during pregnancy and early motherhood in Wakiso district, Central Uganda. Reprod Health 2008, 5:13.

31. Rahman M, Haque SE, Zahan S, Islam O: Noninstitutional Births and Newborn Care Practices Among Adolescent Mothers in Bangladesh. Journal of Obstetric, Gynecologic, \& Neonatal Nursing 2011, 40(3):262-273.

32. Koblinsky M, Matthews Z, Hussein J, Mavalankar D, Mridha MK, Anwar I, Achadi E, Adjei S, Padmanabhan P, Marchal B, De Brouwere V, van Lerberghe W, Lancet Maternal Survival Series steering group: Going to scale with professional skilled care. Lancet 2006, 368(9544):1377-1386.

33. Shahjahan M, Ahmed MR, Rahman MM, Afroz A: Factors affecting newborn care practices in Bangladesh. Paediatr Perinat Epidemiol 2012, 26(1):13-18

34. Karim AM, Admassu K, Schellenberg J, Alemu H, Getachew N, Ameha A Tadesse L, Betemariam W: Effect of Ethiopia's health extension program on maternal and newborn health care practices in 101 rural districts: a dose-response study. PLoS One 2013, 6:e65160.

35. Hill Z, Tawiah-Agyemang C, Okeyere E, Manu A, Fenty J, Kirkwood B: Improving hygiene in home deliveries in rural Ghana: how to build on current attitudes and practices. The Pediatric infectious disease journal 2010, 29(11):1004-1008.

36. Hodgins S, Thapa K, Khanal L, Aryal S, Suvedi BK, Baidya U, Mullany LC Chlorhexidine gel versus aqueous for preventive use on umbilical stump: a randomized noninferiority trial. The Pediatric infectious disease journal 2010, 29(11):999-1003.

37. Howe LD, Manu A, Tawiah-Agyemang C, Kirkwood BR, Hill Z: Developing a community-based neonatal care intervention: a health facility assessment to inform intervention design. Paediatr Perinat Epidemiol 2011, 25(2):192-200.

38. lyengar SD, lyengar K, Martines JC, Dashora K, Deora KK: Childbirth practices in rural Rajasthan, India: implications for neonatal health and survival. J Perinatol 2008, 28(Suppl 2):S23-30.

39. Conrad P, De Allegri M, Moses A, Larsson EC, Neuhann F, Muller O, Sarker M: Antenatal care services in rural Uganda: missed opportunities for goodquality care. Qualitative health research 2012, 22(5):619-629.

40. Waiswa P, Kemigisa M, Kiguli J, Naikoba S, Pariyo GW, Peterson S: Acceptability of evidence-based neonatal care practices in rural Uganda - implications for programming. BMC Pregnancy and Childbirth 2008, 8:21

41. Ayiasi MR, Van Royen K, Verstraeten R, Atuyambe L, Criel B, Garimoi CO, Kolsteren P: Exploring the focus of prenatal information offered to pregnant mothers regarding newborn care in rural Uganda. BMC Pregnancy Childbirth 2013, 13(1):176.

42. Babirye JN, Engebretsen IM, Makumbi F, Fadnes LT, Wamani H, Tylleskar T, Nuwaha F: Timeliness of childhood vaccinations in Kampala Uganda: a community-based cross-sectional study. PLoS One 2012, 7(4):e35432.

43. Nankabirwa V, Tylleskar T, Tumwine JK, Sommerfelt H: Maternal education is associated with vaccination status of infants less than 6 months in Eastern Uganda: a cohort study. BMC Pediatr 2010, 10:92.

44. Mutua MK, Kimani-Murage E, Ettarh RR: Childhood vaccination in informal urban settlements in Nairobi, Kenya: who gets vaccinated? BMC Public Health 2011, 11(1):6. 
45. WHO: Integrated management of pregnancy and childbirth: Managing newborn problems; a guide for doctors, nurses and midwives. Department of Reproductive Health and Research, World Health Organisation, Geneva; 2003.

46. Ornella L, Mothebesoane-Anoh S, Gomez P, Munjanja S: ANC: Opportunities for Africa's Newborns. World Health Organisation, Geneva; 2006:51-62.

47. MoH: Health Sector Strategic and Investment Plan III 2010/2011-2014/ 2015. Promoting People's Health to enahnce socio-economic transformation, Ministry of Health, Kampala; 2010.

48. Conrad P, Schmid G, Tientrebeogo J, Moses A, Kirenga S, Neuhann F, Muller O, Sarker M: Compliance with focused antenatal care services: do health workers in rural Burkina Faso, Uganda and Tanzania perform all ANC procedures? Trop Med Int Health 2012, 17(3):300-307.

49. van Eijk AM, Hanneke MB, Odhiambo F, Ayisi JG, Blokland IE, Rosen DH, Adazu K, Slutsker L, Lindblade KA: Use of antenatal services and delivery care among women in rural western Kenya: a community based survey. BMC: Reproductive Health 2006, 3(2).

50. Nikiema B, Beninguisse G, Haggerty JL: Providing information on pregnancy complications during antenatal visits: unmet educational needs in sub-Saharan Africa. Health Policy Plan 2009, 24(5):367-376.

51. Choudhury N, Ahmed SM: Maternal care practices among the ultra poor households in rural Bangladesh: a qualitative exploratory study. BMC Pregnancy Childbirth 2011, 11:15.

52. WHO: Working with Individuals, Families and Communities to improve Maternal and newborn health. In Bulletin of the World Health Organisation, department of Making Pregnancy Safer; 2010. WHO/MPS/09.04.

53. Babirye JN, Rutebemberwa E, Kiguli J, Wamani H, Nuwaha F, Engebretsen IM: More support for mothers: a qualitative study on factors affecting immunisation behaviour in Kampala, Uganda. BMC Public Health 2011, 11:723.

doi:10.1186/1471-2393-14-114

Cite this article as: Mangwi Ayiasi et al:: Is antenatal care preparing mothers to care for their newborns? A community-based cross-sectional study among lactating women in Masindi, Uganda. BMC Pregnancy and Childbirth 2014 14:114.

\section{Submit your next manuscript to BioMed Central and take full advantage of:}

- Convenient online submission

- Thorough peer review

- No space constraints or color figure charges

- Immediate publication on acceptance

- Inclusion in PubMed, CAS, Scopus and Google Scholar

- Research which is freely available for redistribution 